\title{
Horta escolar: uma abordagem interdisciplinar para uma aprendizagem multidimensional
}

\section{School garden: an interdisciplinary approach to multidimensional learning}

\author{
${ }^{1}$ Expedicto Ribeiro Carvalho Júnior bio_dito@hotmail.com \\ ${ }^{1}$ Célia Regina Tomachuk
}

\section{RESUMO}

A escola é um espaço importante para a formação de indivíduos responsáveis e aptos a colaborar e decidir sobre questões sociais, ambientais e culturais que restabelece suas relações com o meio onde vive. Assim sendo, a horta como ferramenta pedagógica constitui um instrumento que pode articular os conhecimentos restritos às disciplinas do currículo escolar para um saber mais amplo e multidimensional. A metodologia desse projeto foi desenvolvida, pelos alunos, em etapas e foi possível aprender mais do que apenas preparar a terra, plantar e colher. A horta foi transformada em um laboratório vivo onde o crescente interesse, por parte dos alunos, foi visível à medida em que os cuidados com o plantio e com o crescimento das mudas se intensificavam. O contato dos alunos com os vegetais na horta permitiu mudar suas perspectivas de alimentação e atitudes comportamentais com relação ao meio ambiente e com o patrimônio público, de forma positiva.

Palavras-chave: Interdisciplinar. Ensino fundamental. Ciências.

\begin{abstract}
The school is an important space for responsible individuals growth and to enable collaboration and decisions on social, environmental and cultural issues, which in return, reintegrate their relationship to the environment they live. Therefore, from the point of view of a pedagogical tool, a garden is an instrument that can articulate the knowledge of core curriculum to a broader and multidimensional level. The project methodology was developed in stages by the students, in which they were able to learn more than just planting or harvesting the land. The garden was transformed in a live laboratory, where the growing interest by students was visible and intensified as seen in the care with planting and with the growth of seedlings. The students' contact with vegetables from the garden allowed a change in perspective in terms of food and behavioral aptitudes towards the environment and the public property, in a positive way.
\end{abstract}

Keywords: Interdisciplinary. Elementary school. Science. 


\section{INTRODUÇÃO}

O homem na busca por melhores condições de vida, desde o momento de sua inserção no planeta, tem modificado o modo de como se relaciona com o meio ambiente, com os outros da sua espécie e com os seres vivos. E, essas transformações têm possibilitado uma série de conquistas tecnológicas, à custa de uma exploração cada vez mais intensa dos recursos naturais. Alem disso, observa-se problemas, sobretudo no campo ambiental, como fome, miséria, epidemias, pandemias, guerras, corrupção, escassez de minerais, crise hídrica, energética, política e ética são decorrentes desse modo de apropriar-se do ambiente que o homem estabeleceu ao longo dos tempos (PEREIRA, 2014).

Diante deste cenário de reflexão crítico-social dos reflexos da ação antrópica sobre ambiente, a Educação Ambiental (EA) é forjada. O termo "Educação" remete ao processo de produção de conhecimento e ações efetivamente sustentáveis, já o termo “Ambiental” remete ao objeto da educação, ou seja, que a educação possa incumbir-se de produzir conhecimentos que contemplem as múltiplas interrelações existentes no meio natural e social, sem deixar de lado a análise multidimensional dos atores envolvidos nesse processo e suas formas de organização social, numa perspectiva de desenvolvimento, com ênfase na sustentabilidade socioambiental (JACOBI, 2003).

Conforme Cascino (2003), a partir de 1968 a EA é institucionalizada e ganha notoriedade, passando a ser discutida amplamente, não somente pela sociedade civil mas também na esfera política, fato que pode ser evidenciado pela Conferência de Estocolmo em 1972.

No Brasil, a EA institucionaliza-se com a criação da primeira secretaria de Meio Ambiente em 1973, com a intenção de analisar, avaliar, evitar e prevenir desmatamentos e erosões em todo o território nacional e passa a ser exigência constitucional em nível federal, estadual e municipal, com a constituição de 1988 (PAGNOCCHESCHI, 1993). Uma vez institucionalizada a EA ganha verdadeiramente notoriedade na escola, pois esta é o ponto que refrata e reflete, reproduz e produz cultura e desenvolvimento de uma sociedade. Nessa perspectiva a escola precisa superar os limites impostos pelo cognitivismo tecnicista e partir para uma lógica que extrapole os muros da instituição escolar em busca de um processo formativo que seja marcado pelo dialogismo e a formação multidimensional do sujeito (Backthin, 2010).

Para Morin (2001) a educação deve contribuir para a formação do ser humano/pessoa de modo que este possa se tornar um cidadão. Na escola se aprende lições de democracia e cidadania e para tal não pode ficar à margem das questões ambientais se quiser cumprir sua função social (CARLESSO, 2008).

Pensar numa EA de cunho emancipatório é vislumbrar um processo educativo que atenda a uma formação ampla do sujeito/indivíduo, com vistas a contemplar a multidimensionalidade existente nele, ou seja, que o processo educativo contemple os aspectos éticos, estéticos, políticos, cognitivos, indenitários, sociais e morais que abarcam a formação plena do indivíduo. Nessa perspectiva a escola deixa de ser um espaço de cumprimento de uma rotina de reprodução e assimilação passiva de fórmulas e modelos explicativos, em que a impessoalidade e o foco no método fragmentam o saber e tecnicisam o processo educativo limitando o saber apenas no aspecto cognitivo (FREIRE, 2002). A EA pode contribuir para a ruptura desse processo educativo que caracterizou por um tempo a escola e que ainda esse faz presente no cotidiano escolar e que não mais atende à demanda educacional nos atuais dias, para uma lógica de educação marcada pela emancipação do estudante enquanto sujeito do próprio ato de educar com ênfase no dialogismo e interação social, em que estes estudantes possam produzir conhecimentos e cultura de forma autônoma, criativa e crítico-social (BACKTHIN, 2010).

Conforme Ruscheinsky (2002), a escola é um espaço importante para a formação de indivíduos responsáveis e aptos a colaborar e decidir sobre questões sociais, ambientais e culturais que restabelecem suas relações com o meio onde vivem. Nessa direção, a horta escolar pode ser uma ferramenta que estimula o estudante a desenvolver os princípios de responsabilidade e o comprometimento com o ambiente em que vive, com a escola e com a vida em comunidade/sociedade, dentro de uma visão crítico-social, valorizando a sustentabilidade e a manutenção das condições de vida do planeta para as futuras gerações (BERNARDON, 2011). 
Historicamente o cultivo de hortaliças e leguminosas no ambiente escolar é uma ferramenta pedagógica amplamente difundida, por meio da horta escolar e, sobretudo, a partir da Educação Ambiental, representam aquilo que Oliveira (2004) considera como um modo diferente de reinventar o fazer pedagógico, por meio da criação cotidiana de uma alternativa curricular emancipatória.

Conforme Justina (2005) promover uma prática de ensino na qual professores e alunos tenham a oportunidade de desenvolver trabalhos de intervenção na realidade e no cotidiano escolar é uma maneira de ensinar e, ao mesmo tempo, formar alunos reflexivos. De acordo com Marques (1997), quando o estudante se envolve em uma experiência educativa, em que o processo de construção do conhecimento está integrado às práticas vividas, ele deixa de ser apenas um aprendiz e passa a atuar como protagonista da ação.

Assim, a implementação de uma horta como ferramenta de aprendizagem permite que os alunos tenham a oportunidade de conciliar teoria à prática, aplicando o que se aprende na sala de aula. Desta maneira, levarão uma experiência valiosa para vida, já que a saúde do homem está ligada a uma alimentação saudável e rica em vegetais (FRISK 2008).

Os Parâmetros Curriculares Nacionais (PCN) criados pelo Ministério da Educação em 1998 indicam que a aprendizagem de valores e atitudes deve ser mais explorada do ponto de vista pedagógico e o conhecimento dos problemas ambientais e de suas consequências desastrosas para a vida humana são importantes para a promoção de uma atitude de cuidado e atenção com essas questões e de incentivar ações preservacionistas (BRASIL, 1998).

Este trabalho parte da preocupação identificada mediante observação da relação existente entre estudantes e destes com o espaço público de uma escola da rede pública municipal de uma cidade do Vale do Paraíba. Em face de esta demanda identificada, a horta como ferramenta pedagógica constitui então, como um instrumento que poder-se-ia articular os conhecimentos restritos às disciplinas do currículo escolar para um saber mais amplo e multidimensional, que propicie a necessária reflexão/ação/reflexão crítica da realidade e, ao mesmo tempo, reforçar a ligação do educando com o patrimônio público, especialmente a escola?

Com o intuito de responder a esta inquietação, foi implementada uma horta pedagógica na unidade educacional em questão, para buscar promover, junto aos estudantes, um aprendizado mais articulado e efetivo, com base na colaboração, investigação e solução de problemáticas que, uma vez contextualizadas na horta possam auxiliar os estudantes a compreenderem a realidade a qual vivem partindo de um olhar local, com vistas a garantir uma projeção mais ampla e sustentável de toda a variedade e variabilidade de organismos vivos e suas múltiplas e complexas relações. A partir do cultivo de legumes e hortaliças buscou-se desenvolver assuntos que transversalizam a horta e desta maneira podem permitir a aceleração do processo de aprendizagem, além da reflexão crítico-social-ambiental para uma ação cidadã.

\section{AÇÕES DESENVOLVIDAS}

O método de pesquisa utilizado caracteriza-se como sendo descritivo (Gerhardt e Silveira, 2009), visto que tem por objetivo a descrição das características identificadas junto a 35 alunos do $6^{\circ}$ ano de uma escola pública municipal de uma cidade do Vale do Paraíba.

Uma análise qualitativa dos dados coletados por meio da observação e do registro das atividades desenvolvidas no espaço da horta escolar em dialogia com os pesquisadores, pensadores e estudiosos da EA foi realizada. Nessa direção, Gil (2008) afirma que a análise qualitativa, em investigações científicas, permite ao pesquisador aprofundar o conhecimento das questões relacionadas ao fenômeno em estudo.

Inicialmente foi feita uma observação do comportamento dos alunos do $6^{\circ}$ ano da escola em questão, durante o período do intervalo escolar com ênfase na observação da dinâmica do relacionamento entre os pares e a relação destes 
estudantes com o ambiente escolar físico, buscando identificar a relação de pertencimento dos alunos para com o ambiente escolar, bem como a cultura alimentar destes estudantes.

Posteriormente escolheu-se um espaço na escola para a construção de uma horta educativa que pudesse ser utilizada como ferramenta pedagógica e impactar a realidade observada, dentro de uma perspectiva emancipatória. Uma vez definido o espaço, os canteiros para receber as hortaliças e leguminosas foram preparados e procedeu-se com revolvimento do solo, adubação orgânica e posterior plantio. Todas as atividades, desde o plantio, tratos culturais, irrigação até a colheita foram desenvolvidas pelos professores da unidade escolar em questão, pelos alunos participantes do projeto e por dois membros da comunidade local que se voluntariaram ao projeto, que foi desenvolvido em cinco etapas, descritas abaixo:

Etapa 1:

Nesta etapa os alunos foram divididos em 5 grupos, ficando cada grupo encarregado da preparação, plantio e cultivo em um dos cinco canteiros da horta. O enfoque dado fez referência aos cuidados e ao preparo do solo para receber uma semente ou muda. Cabe ressaltar a importância da adubação, tendo em vista que há duas maneiras de fazê-la e que se privilegiou mais a adubação orgânica buscando-se harmonizar as relações ecológicas, os ciclos biogeoquímicos e o desenvolvimento sustentável. Posteriormente os estudantes foram desafiados a buscar informações e mobilizar conhecimentos, habilidades e ações voltadas à preparação do solo para o tipo de hortaliça que sua equipe iria cultivar. O processo de pesquisa do tipo de hortaliça a ser cultivada antecedeu a pesquisa da forma de adubação e da proporção desta.

\section{Etapa 2:}

Nesta etapa, após a preparação do solo, procedeu-se o plantio e o acompanhamento do processo de germinação com ênfase no processo de fotossíntese e sua importância para produção do próprio alimento nos vegetais e, ao mesmo tempo, a relevância de se cultivar hortaliças e leguminosas.

\section{Etapa3:}

Nesta etapa foi privilegiado o acompanhamento do crescimento das hortaliças plantadas ao longo de quatro semanas. Após esse período o desenvolvimento das diferentes hortaliças foi comparado, com base nos dados de observação semanal que foram compilados em relatórios estruturados, preenchidos pelos estudantes. Nesta etapa questões como insolação, tempo de ciclo de vida de plantas, morfologia das plantas, irrigação, adubação foi problematizada. Ainda nesta etapa foi proposto aos grupos a pesquisa e a construção de receitas com base nas hortaliças por eles cultivadas, assim como os benefícios destes nutrientes para a saúde.

\section{Etapa 4:}

Após o acompanhamento do desenvolvimento das hortaliças e leguminosas foi necessário identificar o período mais propício à colheita. Nesta etapa, familiares dos alunos foram convidados a participar da colheita e preparação de um lanche natural feito com os vegetais colhidos. Nesta oportunidade permitiu-se uma interação entre os estudantes e suas respectivas famílias. Neste encontro, uma cartilha com o compilado de receitas elaboradas pelos grupos de estudantes foi entregue às famílias para que na prática os pratos pudessem estar mais coloridos e igualmente aproveitar ao máximo tais cultivares não só no sentido ambiental mas também voltado a saúde.

\section{Etapa 5:}

Nesta etapa os alunos fizeram uma caminhada pelas ruas do bairro no entorno da escola para entregar a cartilha elaborada por eles e buscar realizar o processo de multiplicação de conhecimento. 


\section{RESULTADOS E DISCUSSÕES}

O crescente interesse por parte dos alunos na medida em que se intensificavam os cuidados com o plantio e com o crescimento das mudas foi notório. Associações com conhecimentos como solo, água, germinação, defensivos agrícolas e luz do sol foram mais facilmente compreendidas em atividades ao ar livre, em grupo, observando a natureza seguindo o seu curso, tal qual acontece no cotidiano vivenciado pelos estudantes, do que em aulas teóricas unidirecionais que ocorrem em sala de aula.

Nesse sentido foi percebido que a horta escolar é o espaço propício para que as crianças aprendam os benefícios de formas de cultivo mais saudáveis. Além disso, houve o desenvolvimento de hábitos de alimentação mais variada e melhor, pois como se sabe, as crianças em geral não gostam de comer verduras e legumes e o fato de cultivar o alimento ajudou a diminuir a resistência em fazer uso do alimentos, especialmente porque é conhecida a origem dos vegetais e a maneira como foram cultivados. Aumentar o consumo de frutas, legumes e verduras tem sido uma das principais recomendações e um desafio para a saúde pública. Conforme Gomes (2007), cada vez mais instituições nacionais de saúde e agricultura, representantes da indústria e de organizações internacionais, têm trabalhado para acessar esses obstáculos e discutir formas de promover o consumo de frutas, legumes e verduras ao redor do mundo.

A participação de todos os alunos na construção da horta escolar desde a preparação do solo permitiu o envolvimento de cada educando por inteiro. A atitude individual vivenciada pelo grupo contribuiu para estreitar laços entre os estudantes e destes com os bolsistas e com a unidade escolar. Nessa perspectiva Boff (1999) afirma que cuidar é mais que um ato; é uma atitude. Portanto, abrange mais que um momento de atenção, de zelo e de desvelo. Representa uma atitude de ocupação, preocupação, de responsabilização e de envolvimento afetivo com o outro.

Com as atividades desenvolvidas, os alunos ficaram sensibilizados com o cuidado e a preservação do ambiente escolar. Neste aspecto, passaram a identificar e apontar as áreas mais degradadas na escola, no bairro e na cidade. Jardins abandonados, bueiros entupidos e até mesmo a falta de higiene na sala de aula/escola. Além disso, os estudantes passaram a ter uma atitude diferente com relação a fauna que habita as dependências da escola. Passaram a dar mais atenção e cuidado com os animais que vivem no entorno da escola e os hábitos alimentares dos mesmos. Tais modificações comportamentais nos levam a inferir que foi promovido o despertar de competências e valores éticos que conduzirão o repensar e nova consciência, dos alunos, em suas atitudes diárias e, por assim dizer, em suas intervenções diretas no meio ambiente em que vivem.

Os estudantes, ao explorar o espaço escolar, tiveram a oportunidade de vivenciar as potencialidades de um ambiente bem cuidado e passaram a valorizar o espaço público, não somente o escolar, mas também aquele que está próximo a sua residência e por consequência, na sua cidade.

Comentários dos estudantes sobre evitar desperdício da merenda e dos recursos como água e luz passaram a fazer parte das conversas em grupos. Isto sugere que por meio da implantação dessa horta diversos assuntos inerentes ao cotidiano dos alunos e das suas famílias, como desenvolvimento sustentável, responsabilidade social, melhoria na qualidade da alimentação, importância de trabalhar de maneira sustentável e com respeito aos ciclos e potencialidades do meio ambiente, puderam trazer novos significados para uma questão simples que é aproveitar os recursos de forma acessível a todo o cidadão.

O espaço da horta escolar é caracterizado por Capra (2007) como um local capaz de religar as crianças aos fundamentos básicos da comida e ao mesmo tempo integra e enriquece todas as atividades escolares. Despertam para conservar o ambiente e a trilhar os caminhos para alcançar o desenvolvimento sustentável e não para a depredação. 
Outro resultado observado diz respeito a compreensão da abordagem sobre conceitos de sustentabilidade como ferramenta de trabalho e de reflexão interdisciplinar entre aluno e professor. Foi verificado uma mudança de comportamento dos alunos, vista pelos professores como influência positiva proporcionada pelo trabalho com a horta, em resposta ao contato físico com a terra e as atividades realizadas em grupo, o que pode favorecer o processo educativo da sensibilidade, do trabalho coletivo, da consciência política, da cidadania crítica e da postura cuidadosa em relação ao planeta.

Durante o processo de pesquisa para a escolha dos tipos de hortaliças a serem cultivadas, percebeu-se o desconhecimento dos estudantes em relação a hortaliças, devido ao baixo consumo destas em casa. A escolha de vegetais ocorreu por duas razões: aparência física do vegetal (cor, brilho e tamanho de folha) e experiência prévia (se já haviam consumido o vegetal). O grupo 1 escolheu alface crespa e argumentou que este tipo de hortaliça todos do grupo consumiam, ou seja era o consenso dentro do grupo. O grupo 2 escolheu rúcula e disse que apesar de alguns membros do grupo não conhecerem a hortaliça, acharam "bonitas" as folhas e gostariam de cultivar. O grupo 3 escolheu acelga, pois na escola era comum ter salada de acelga e disseram que "todo mundo" come acelga. O grupo 4 escolheu couve manteiga e disseram que todos do grupo gostavam de couve. $\mathrm{O}$ grupo 5 escolheu rabanete e argumentou que não sabiam o que cultivar e por isso foram pesquisar e viram que o rabanete tem um ciclo de vida de 23 a 30 dias podendo colher rapidamente.

Como cada tipo de hortaliça necessita de um tipo de condição climática e de umidade, cabendo uma nova pesquisa para ver o modo de preparo do solo, calagem, adubação, irrigação, plantio e escolha por semente ou muda. Nesta fase, ouve muita dúvida, pois na medida em que comparavam os conhecimentos extraídos de pesquisas na rede mundial de computadores com entrevistas junto a membros da comunidade que mantinham hortas, perceberam que existem múltiplas técnicas e que dentro da hortaliça escolhida também há uma variedade de espécies com indicações de técnicas distintas para o cultivo.

O grupo 1 ao vivenciar uma diferença no modo de cultivo e preparo do solo encontrado por meio da pesquisa e da entrevista com um cultivador de horta do bairro, resolveu separar o canteiro no meio aplicar as duas técnicas para comparar os resultados e posteriormente apresentar uma devolutiva ao cultivador do bairro como forma de auxiliá-lo em seu trabalho. As duas técnicas diferiam basicamente na colocação de uma camada de folhas sobre o solo e a presença de um quebra sol sobre o canteiro. O cultivador não utilizava as folhas, nem tão pouco o quebra sol. Foi possível observar que a alface crespa, cultivado com uma camada de folhas sobre o solo e com o quebra sol, apresentou melhor desenvolvimento e as folhas apresentaram-se mais verdes e maiores. Os alunos alegaram que a diferença se deu basicamente em função de as folhas secas colocadas sobre o solo funcionarem como uma espécie de barreira que impedia a evaporação de água, mantendo o solo mais úmido e o quebra sol permitiu o controle de insolação reduzindo, desta forma, a perda de água da planta por transpiração. Tal conclusão dos estudantes ocorreu depois de estes realizarem nova pesquisa para apresentarem suas sugestões ao cultivador do bairro.

Ao comparar os tipos de cultivos entre si percebeu-se que há uma diferença de ciclo de vida e que nem todas as hortaliças se desenvolvem rapidamente em determinada época do ano, visto que fatores como luz, temperatura e umidade são importantes a todo e qualquer forma de cultivo. Ao serem questionados sobre um lugar que teriam visitado e se poderiam se lembrar de um alimento característico, responderam imediatamente que sim e referiam-se a um sítio na proximidade que pertencia a algum parente e indicavam um tipo de fruta que em geral era característico de Mata Atlântica, pois é a mata que ainda existe em fragmentos na região.

Os estudantes ao analisarem as diferenças morfológicas entre as folhas das hortaliças cultivadas perceberam a diferença de coloração, tamanho, forma e textura destas plantas e atribuíram tais diferenças ao clima ideal para seu cultivo, disponibilidade de água, luz solar e ao solo. Ao analisarem mais profundamente, observando os lugares de onde os hortaliças escolhidas teriam surgido, percebeu-se uma variedade de lugares distantes do Brasil e ao conectarem as origens das hortaliças com as especiarias encontradas durante o período das navega- 
ções e dos descobrimentos, os estudantes tiveram a oportunidade de contextualizar os conhecimentos cognitivos assimilados nas aulas de história, geografia, matemática e ciências.

Durante o processo de pesquisa para a construção de receitas, observou-se que as equipes se dedicaram a estabelecer receitas distintas daquelas que tinham e/ou faziam uso alimentar em casa. Nesta etapa, a curiosidade de preparar os pratos embalaram os estudantes e percebeu-se que na medida em que desejavam se alimentar dos seus cultivarem deixavam de resistir à ingesta de hortaliças e paralelo a isso, por iniciativa própria, buscavam informações nutricionais dos cultivares, como forma de alicerçar o argumento para convencer a si e a outros a se alimentarem delas.

Uma vez construída a cartilha, esta foi entregue às famílias e à comunidade. Uma nova surpresa foi vivenciada pelos estudantes, pois a maioria das receitas construídas por eles eram conhecidas da comunidade e que em virtude da resistência das crianças, haviam deixado de executá-las. Ao saber deste dado os estudantes relataram que o fato de não terem acesso a determinados alimentos, associados a sua forma, textura e cor, deixam de atrair e/ou cativar as crianças para o consumo, o que de certa forma acabavam por gerar um ciclo, uma vez que as crianças não consumiam pois não tinham oportunidade de conhecer e as famílias não faziam pois as crianças declaravam não querer.

\section{CONSIDERAÇÕES FINAIS}

A avaliação das atividades na horta escolar, das discussões preliminares até a colheita, foi positiva no que diz respeito ao engajamento das turmas e dos professores de forma geral.

O envolvimento inicial foi tímido, porém conforme as atividades foram se intensificando e os resultados da horta começaram a surgir, mais alunos demonstraram interesse, em que a participação dos professores da turma foi primordial para formar o diálogo com os demais professores e fazer com que a horta fosse motivo de assunto nas diversas disciplinas.

A limitação do espaço e as condições climáticas dificultaram o desenvolvimento conforme planejado, contudo a organização das turmas para o gerenciamento da horta minimizaram os impactos gerados pelo longo período sem chuvas, estiagem.

Como sequência a este trabalho, há a intenção de se criar um painel ou um blog com atualização frequente para que todos, inclusive as famílias, pudessem acompanhar a evolução do projeto por fotos e matérias temáticas, contudo não houve tempo hábil para por em prática. Esta interação futuramente possibilitará com que todos façam comentários e ou sugestões em diversos níveis, aproximando as pessoas das atividades da escola.

Foi notório observar a alteração no ambiente escolar com a implantação deste projeto, pois promoveu a mudança de comportamento dos alunos com relação ao desperdício da merenda, diminuição de resíduos jogado no pátio e corredores e a inclusão do tema meio ambiente e preservação dos recursos nos diálogos em sala de aula.

Foi possível inferir que à partir da horta como ferramenta de aprendizagem há uma redução na resistência de os professores trabalharem a multi e a interdisciplinaridade, visto que estes profissionais acabam por evidenciar, nestas atividades, que o conhecimento não está restrito a um reduto de saber que é limitado.

Enfim, para além dos momentos de planejamento coletivo de professores deixarem de ser burocráticos e de transmissão de recado, passaram a ser interativos e de planejamento democrático, permitindo a reflexão crítica destes profissionais em relação a sua prática, culminando em uma ação mais emancipatória do fazer pedagógico, permitindo que os estudantes atuassem de forma autônoma e sendo estimulados/desafiados ao aprender a aprender. 


\section{REFERÊNCIAS}

BAKHTIN, Mikhail Mikhailovich. Marxismo e filosofia da linguagem: problemas fundamentais do método sociológico na ciência da linguagem. 14a ed. São Paulo: Hucitec, 2010. 200p.

BOFF, Leonardo. Saber cuidar: ética do humano - compaixão pela terra. Petrópolis: Vozes, 2008. 199p.

BRASIL. Secretaria de Educação Fundamental. Parâmetros Curriculares Nacionais: Ciências Naturais e Biologia - Brasília: MEC/SEF, 1998.

CASCINO, Fabiano. Educação ambiental: princípios historia formação de professores. São Paulo: SENAC, 1999. $110 \mathrm{p}$

FREIRE, Paulo. Pedagogia da autonomia: saberes necessários à pratica educativa. São Paulo: Paz e Terra, 2002. 144p.

FREITAS, Denise (Org.). Cultura no espaço da diversidade, sustentabilidade e inclusão. São Carlos: EdUFSCar, 2014. 71p.

FUNDO NACIONAL DE DESESENVOLVIMENTO DA EDUCAÇÃO (FNDE/MEC). Educando com a horta escolar. 2005. Disponível em: http://www.educandocomahorta.org.br Acesso em: 12 abril 2015.

MORGADO, Fernanda da Silva. A horta escolar na educação ambiental e alimentar: experiência do Projeto Horta Viva nas escolas municipais de Florianópolis. 2006. 45p.

MORIN, Edgar. Os sete saberes necessários à educação do futuro. Tradução de Catarina Eleonora F. da Silva e Jeanne Sawaya. 2a ed. São Paulo: Cortez. 118p.

NOGUEIRA, Wedson Carlos Lima. Horta na escola: uma alternativa de melhoria na alimentação e qualidade de vida. Anais $8^{\circ}$ Encontro de Extensão da UFMG. Belo Horizonte: UFMG, 3 a 8 de outubro de 2005.

RUSCHEINSKY, Aloísio (Org.). Educação ambiental: abordagens múltiplas. Porto Alegre: Artmed, 2002. 183p. 